\title{
A ÁFRICA ANTIGA NO ENSINO de hISTÓRIA
}

Raquel dos Santos Funari ${ }^{1}$

\section{Resumo}

O artigo trata da África Antiga no ensino de história no Brasil. Trata, ainda, das maneiras como a África Antiga tem sido e pode ser retratada na educação, para propor um retrato mais complexo, profundo e inspirador. Volta-se, em seguida, para a presença humana na África, por meio de situações de aprendizagem. O Egito destaca-se como parte da cultura africana. Conclui-se por enfatizar o papel das aulas de História para reconhecer a presença africana muito antes e para além do período moderno.

\section{Palavras chave}

África; Ensino de História; Egito Antigo; História Antiga.

\begin{abstract}
The paper deals with the subject of ancient Africa in teaching of history in Brazil. It deals with the ways in which African Antiquity has been and can be portrayed in education, to propose a more complex, profound and inspiring picture. It turns to the antiquity of human presence in Africa, through learning situations. Egypt shines as part of African culture. It concludes by stressing the role of history classes for the recognition of African presence much before and beyond the modern period.
\end{abstract}

\section{Key-words}

Africa; Teaching of history; Ancient Egypt; ancient history.

\footnotetext{
${ }^{1}$ Doutora - Universidade Estadual de Campinas, Brasil. E-mail: raquelsfunari@uol.com.br
} 


\section{Introdução: a África para além do lugar comum}

Quando se fala em África, há uma tendência, quase que inevitável, no Brasil, a tratar da África subsaariana de época moderna, a partir do século XV. De fato, desde cedo, aprendemos na escola, nos livros didáticos e nas salas de aula, sobre a expansão marítima portuguesa e a ação colonizadora, primeiro no continente africano, depois na América. Em seguida, e de maneira em tudo lógica, a relação entre a colônia portuguesa do nosso lado do Atlântico e a os do outro lado tornam-se capital na narrativa sobre nossa História. Os cativos africanos contribuíram, quase desde o início, para a cultura brasileira, com a maioria da população africana ou afro-descendente até, ao menos, a abolição da escravidão, em 1888. A História posterior tampouco pode ser dissociada da presença afro-brasileira, a tal ponto que samba se tornou sinônimo de nosso país, tanto nas versões populares, quanto sofisticadas, como na Bossa Nova. O Brasil não existe sem sua matriz africana subsaariana.

Mas, nem tudo se resume a isso, por mais relevante que seja. Nossa ligação com a África é muito mais antiga e profunda, mas nem sempre reconhecida ou associada à África. Neste artigo, viso a tratar do Ensino de História, essa área de atuação tão importante, ainda que nem sempre avaliada com a devida atenção. A imensa maioria de pessoas toma conhecimento do passado, da História como narrativa, por meio da escola fundamental e secundária. Os profissionais da História, professores e pesquisadores, não são nem 1\% da população. Como professora, supervisora e profissional do Ensino de História isso sempre me pareceu um aspecto essencial a ser levado em conta. O que as crianças aprendem sobre o passado, na escola, será o que forjará os cidadãos.

Daí meu interesse especial sobre o tema da África antiga na escola. A África moderna, marcada pela escravidão, pela dominação colonial e pela pobreza, pode levar ao reforço de estereótipos, cujos efeitos deletérios, na nossa sociedade, podem ser muito negativos. Tanto o desenvolvimento econômico apenas parcial, como a persistência secular das desigualdades sociais, muitas vezes têm sido associados, de maneira injustificada, à herança africana, seja pela escravidão, seja pela noção de desvalorização do trabalho, a ela associada.

No entanto, nada disso passa pelo crivo de uma perspectiva crítica, que procura observar as realidades para além das aparências. A modernidade vai muito além, e as razões para a persistência das desigualdades, do racismo e das discriminações são múltiplas, mas muitas delas relacionadas a uma visão estreita do continente africano. Neste artigo, vou tratar de como a Antiguidade da cultura africana tem sido e pode ser retratada, no ensino, de modo a mostrar um quadro mais complexo, profundo e inspirador. 


\section{A Antiguidade da humanidade africana}

Em primeiro lugar, há que lembrar a antiguidade humana, que esteve, por milhões de anos, restrita ao continente africano. Inúmeras espécies de primatas, nossos antepassados diretos ou indiretos, viveram na África: o berço mais longínquo da humanidade. Mesmo se nos restringirmos à nossa espécie, homo sapiens, foi a África a origem de todos os humanos. Até 2017, os dados genéticos e da morfologia dos esqueletos indicavam uma antiguidade entre 50 e 150 mil anos, na África Oriental. Pesquisas e datações arqueológicas recentes elevaram esses vestígios a 300 mil anos, no Marrocos. Isso não nos deve estranhar, pelos períodos de continuidade de ocupação vegetal e animal do Saara, uma savana por longos milênios, de maneira intercalada.

Como isso aparece na escola, no Brasil? Muito pouco, seria a resposta simples e imediata e por diversas razões. Em primeiro lugar, o estudo do passado mais distante e das origens humanas merece muito pouco espaço nos livros didáticos e menos ainda na sala de aula. Nos manuais, esse passado mais profundo sequer é tratado em muitas obras e isso reflete, também, a própria formação dos professores de História, pois rara vez esses temas aparecem nos currículos dos cursos de História. Isso, em parte, deve-se ao fato de os humanos primitivos serem colocados no âmbito das espécies biológicas, a serem tratados, na medida do possível, nas aulas de Biologia. Como quer que seja, os 99\% da História Humana, até a invenção da escrita, cinco mil anos atrás, são tratados com rapidez ou ignorados. Na medida em que o professor tem uma formação muito frouxa sobre tais temas, nada mais natural que isso contribua para que seja deixado de lado na sala de aula. O resultado é desconsiderar que todos os humanos são africanos ou afro-descendentes.

Minha experiência, tanto como autora, como na sala de aula, mostra o potencial desse estudo, com as crianças, da profundidade histórica africana. Como autora, a inclusão de tais questões nos compêndios tem sido muito bem recebida. Tenho conversado com professores, supervisores e coordenadores nas escolas e sempre que há a inclusão dessa discussão. É evidente que tais questões não são de fácil tratamento pelo fato mesmo de a formação ser deficitária nesses temas. Mesmo assim, há imensa curiosidade e interesse, tanto pelos profissionais, como pelos alunos. Parece mesmo ser uma descoberta libertadora: a Antiguidade da humanidade africana retoma a noção de compartilhamento de valores humanos, para além das particularidades históricas e culturais. Em outras palavras, todos nós somos humanos, todos temos os mesmos antepassados comuns e todos nós somos responsáveis pelos destinos de todos, de toda humanidade.

Isso reflete valores espirituais profundos, tanto de vertentes religiosas, como laicas: amar o outro como a si mesmo, todo somos iguais, todos somos diferentes, 
mas com as mesmas prerrogativas. São, segundo alguns estudiosos como François Hartog, as três abordagens: a passadista, a iluminista e a pós-moderna. Não importa: todas compartilham, de maneira diversa, o respeito ao outro. No caso específico, a consciência da comum origem africana dissolve qualquer vestígio de justificação para discriminações. Na sala de aula, vivencio como as crianças se encantam com esse tema, pois encontram na humanidade comum a todos os seres humanos uma maneira de superar as clivagens entre elas.

Em seguida, há o grande tema da África na Antiguidade, a partir da invenção da escrita, cerca de 3.200 a.C. Os livros didáticos de História dedicam parte substancial ao mundo antigo, os currículos estaduais e federal tratam desse período (3.200 a.C.-476 d.C.) e culturas em detalhe. A Base Nacional Comum Curricular, divulgada em 2017, apresenta os seguintes itens:

BNCC 6 ano, p. 370

- A invenção do mundo clássico e o contraponto com outras sociedades.

- Povos da Antiguidade na África (egípcios), no Oriente Médio (mesopotâmicos) e nas Américas.

- As noções de cidadania e política na Grécia e em Roma

- Domínios e expansão das culturas grega e romana

- Significados do conceito de "império" e as lógicas de conquista, conflito e negociação dessa forma de organização política

- As diferentes formas de organização política na África: reinos, impérios, cidades-estados e sociedades linhageiras ou aldeias

- O Mediterrâneo como espaço de interação entre as sociedades da Europa, da África e do Oriente Médio

\section{P. 371}

- Senhores e servos no mundo antigo e no medieval

- Escravidão e trabalho livre em diferentes temporalidades e espaços (Roma Antiga, Europa medieval e África)

\section{P. 372}

- Identificar aspectos e formas de registro das sociedades antigas na África, no Oriente e nas Américas, distinguindo alguns significados presentes na cultura material e na tradição oral dessas sociedades.

No caso do Estado de São Paulo (http:/ / www.educacao.sp.gov.br/ sao-paulo -faz-escola) isso também fica claro:

- Civilizações do Oriente Próximo 
- O Egito Antigo e a Mesopotâmia

- África, o "berço da humanidade"

- Reconhecer a África como o lugar de surgimento da humanidade a partir de dados e vestígios arqueológicos

Pode avaliar-se o material didático utilizado no Estado de São Paulo por um trecho sobre a herança comum africana:

Situação de aprendizagem 3: África, o berço da humanidade.

Atividade - Vestígios arqueológicos encontrados na África.

A atividade tem como objetivo analisar a importância do continente africano para as pesquisas arqueológicas sobre as diferentes etapas do desenvolvimento da humanidade. Estudiosos de diferentes áreas têm atuado em pesquisas em busca de vestígios, artefatos, vasos de cerâmica, restos de fogueira o que tem permitido mostrar a importância do continente africano para a história da humanidade.

A terceira proposta de aprendizagem tem como objetivo mostrar, a partir de um painel ilustrado com diferentes artefatos, feito preferencialmente em um esboço do mapa da África, os vestígios da nossa história. Sabemos que nossos antepassados mais antigos surgiram no continente africano e durante a maior parte da história ali viveram. As espécies que deram origem ao moderno ser humano viveram na África há cerca de sete milhões de anos. Os primeiros seres humanos que saíram da África o fizeram apenas há cem mil anos. Portanto, mais de 95\% da nossa história foram no continente africano. Já por isto, é importante estudarmos a África, berço da humanidade.

Outra passagem também é significativa a vale a pena citar:

A África é, portanto e em todos os sentidos, o berço da humanidade. Os mais antigos hominídeos foram localizados na África oriental (Etiópia, Quênia, África do Sul).

Essa a primeira importância da África. Em seguida, e mais perto de nós no tempo, é importante conhecermos a rica História da África nos últimos dez mil anos, período que corresponde à época em que vivemos (Holoceno). $\mathrm{Na}$ África, existe uma grande diversidade lingüística, mas os estudiosos agruparam as línguas e dialetos em quatro grandes grupos. Os dois grupos mais recentes, de fora da África são as línguas germânicas na África do Sul e as línguas asiáticas em Madagascar. No continente, propriamente, há 
quatro grandes grupos, de norte a sul: afro-asiático, Nilo-saariana, niger-cordofânio e coisano. Os afro-asiáticos ocupam toda a parte Mediterrânea, mas também parte do Oceano Índico. Esses grupos parecem ter se originado de alguma área a nordeste do continente, há milhares de anos, tendo originado línguas como o antigo egípcio, mas também línguas que hoje associamos à Ásia, como o hebraico e o árabe. Portanto, esses povos do Oriente Médio têm uma ligação umbilical com a África.

O Egito está na África, as línguas ali usadas no passado e no presente são africanas: o que se quer dizer com o caráter africano do Egito? Esta perspectiva visa a ressaltar as contribuições africanas, definidas por diferença com outras importantes civilizações antigas, como as mesopotâmicas (Sumérios, Babilônicos, Assírios), hebraica, grega e romana, para citar as mais conhecidas. Trata-se, claro, de um exercício difícil e arriscado, pois somos todos seres humanos e as civilizações mencionadas acima interagiram entre si e não se pode separar elementos puramente africanos, asiáticos ou europeus. Portanto, a intensão não é isolar os elementos africanos dos outros, mas mostrar como diversas características africanas estão presentes na civilização egípcia e, também por isso, tiveram tanta acolhida em outras partes do mundo.

Talvez o elemento cultural africano mais forte da civilização egípcia e que tenha tido maior repercussão seja a religiosidade, em sua especificidade: crença em almas, na vida após a morte e na ressurreição. Já no início do período faraônico, quando temos registros escritos em hieróglifos (fim do quarto milênio a.C.), os egípcios acreditavam que a pessoas possuíam diversos tipos de espírito e corpo: khat (corpo), jb (coração), $r n$ (nome), $k a$ (espírito da vida), shut (a sombra), ba (a alma imortal). Essa riqueza única de aspectos espirituais ligados à vida está bem enraizada nas tradições africanas, sendo conhecidas, em outras formas, na espiritualidade dos povos da África subsaariana. Não por acaso, povos de outras regiões do mundo, em diferentes épocas, inspiraram-se nas concepções de alma dos egípcios, desde os gregos antigos até os modernos adeptos da religião espírita, tão difundida, ademais, no Brasil.

Ainda no campo espiritual e religioso, destaca-se o tema da ressurreição, presente no mito de Osíris. Osíris foi morto por seu irmão Sete, que ambicionava o seu trono. Ísis conseguiu trazê-lo de volta à vida por meio de um feitiço aprendido com seu pai, o que permitiu que ela engravidasse de Osíris, antes de seu retorno ao reino dos mortos, dando a luz ao deus Hórus. Essa concepção de renascimento foi tão forte que, durante o Império Romano (31 a.C.-410 d.C.) o culto a Ísis tornou-se um dos mais populares. A crença na ressurreição mais antiga que se conhece é egípcia e embora ela tenha surgido também em outras partes do planeta, de forma independente, as noções egípcias foram de 
particular relevância para a difusão e êxito posterior do cristianismo, difundido muito cedo no Egito, já no primeiro século d.C., e, depois, a partir do século XV, na África subsaariana, por essa junção de expectativas sobre a vida após a morte.

Para além da espiritualidade, há outros aspectos da civilização egípcia que são pouco comuns em outros povos e que remetem ao continente africano: $o$ papel da mulher. Enquanto as civilizações orientais e gregas confinavam a mulher a um papel social muito limitado, a mulher egípcia teve, desde o início do período histórico, no final do quarto milênio, uma participação social destacada. O corpo da mulher egípcia era representado com muito mais liberdade, ela podia mostrar não só sua formosura, como os adornos femininos foram valorizados desde cedo e muitas dessas representações femininas e adornos chegaram até nós, graças às pesquisas arqueológicas. As mulheres foram valorizadas pela sua fertilidade, mas também por sua beleza e capacidade intelectual e política. Algumas rainhas ficaram muito famosas, como Hatshepsut (1508-1458 a.C.), Nefertiti (1370-1330) e Cleópatra (69-30 a.C). Hatshepsut atuou como faraó, Nefertiti foi a rainha e conselheira do faraó Akenaton, introdutor do monoteísmo, e é hoje reconhecida como uma das mais belas mulheres de todos os tempos, a julgar por sua estátua conservada no Museu de Berlim. Cleópatra, embora de família macedônica, atuou como rainha do Egito à maneira e tradição da terra e foi considerada uma das mulheres mais poderosas, inteligentes e charmosas de todos os tempos. Também neste aspecto, não se pode deixar de notar que em muitas sociedades tradicionais africanas a mulher tem uma vida social intensa, à diferença da segregação comum em outras civilizações, em todos os aspectos, inclusive como líderes espirituais (quem não pensa, aqui, nas mães de santo?).

No currículo do Estado de São Paulo, entre outras passagens, uma delas mostra a ligação umbilical entre o Egito Antigo, no continente africano, e o Oriente:

Propostas de questões para a avaliação final.

Questão 1: (aberta)

Qual a origem do termo "crescente fértil?".

RESPOSTA.

O termo "Crescente Fértil" foi criado pelo arqueólogo norte-americano James Henri Breasted, no início do século XX. Este grande estudioso do Oriente Médio propôs esse nome para designar o arco, em forma de lua crescente, entre o Golfo Pérsico, Mesopotâmia, Síria e Líbano, Palestina e Egito. Essa área encontra-se entre os continentes Asiático e Africano, vizinho 
à Europa, o que favoreceu uma biodiversidade incomum. Essa área testemunhou, desde o fim do Pleistoceno (9.500 a.C.), o desenvolvimento da agricultura, da cerâmica, das cidades e das grandes civilizações. O nome "Crescente Fértil" refere-se à fertilidade do solo, quando irrigado por rios, para a agricultura, mas também à fertilidade cultural que permitiu o surgimento de tantas civilizações. Já a imagem da lua crescente teve inspiração na imagem formada no mapa (entre o Golfo Pérsico e o Alto Egito, em forma de um arco, que passa pelo Líbano e Palestina), mas, também, na lua crescente que é o símbolo do Islã, religião dominante na região hoje.

Habilidades e competências: ao responder a esta questão, o aluno pode demonstrar que domina a norma culta da Língua Portuguesa e que consegue identificar, a partir da leitura de textos o significado da expressão "Crescente Fértil"; pode, também, mostrar-se capaz de relacionar informações para construir uma argumentação consistente.

\section{Conclusão}

O ensino de História tem merecido atenção crescente, em particular pelo fato de formar os futuros cidadãos. Há um consenso entre os analistas que a formação educacional é condição necessária para que o país possa tanto se desenvolver, como fazer com que esse desenvolvimento beneficie à maioria e possa contribuir para a diminuição das diferenças sociais. Esse foi o caminho trilhado por países como a Coréia do Sul, Portugal, o Chile, ou Botswana, em ordem decrescente de correlação entre nível de vida e educação. $O$ que importa, no entanto, é que o investimento em Educação geral induz a melhora das condições de vida, mesmo nos casos de países pobres, como no caso da Índia.

Como parte dessa formação, o conhecimento histórico ocupa posição de destaque, pois fornece um contexto genérico que, aliado à capacidade de expressão que não pode ser dele separado, ampara o juízo crítico de qualquer adulto. No caso específico do nosso país, marcado por diferenças sociais das maiores no mundo, a educação assume um papel estratégico. Tanto na Base Nacional Comum Curricular como a currículo do Estado de São Paulo, aqui mencionados, o continente africano, em sua antiguidade, aparece com destaque em dois grandes tópicos: a África como berço comum da humanidade e a civilização egípcia no contexto do continente africano. O ensino da História, formador do futuro cidadão, pode contribuir, por esse meio, para instigar uma perspectiva mais ampla, crítica e humanista. Esse um papel de alta relevância da História Antiga. 


\section{Agradecimentos}

Agradeço a Margareth Marchiori Bakos, Ciro Flamarion Santa Cardoso, André Leonardo Chevitarese, Gabriele Cornelli, Lourdes Conde Feitosa, Júlio César Gralha e Lynn Meskell. Menciono, ainda, o apoio institucional do Departamento de História da Unicamp. A responsabilidade pelas ideias restringe-se à autora.

\section{Bibliografia}

ALBUQUERUQE, W.R.; FRAGA FILHO, W. Uma História do Negro no Brasil. Brasília, Fundação Cultural Palmares, 2006.

BAKOS, M.; FUNARI, R. S. . História da tradição clássica no Brasil dos séculos XIX e XX. Egito antigo no Brasil: egiptologia e egiptomania. In: André Leonardo Chevitarese; Gabriele Cornelli; Maria Aparecida de Oliveira Silva. (Org.). Tradição Clássica e o Brasil. 1 ed. Brasília: Fortium/Archai, 2008, v. 1, p. 143-152.

BAKOS, M.M. Egiptomania, o Egito no Brasil. São Paulo, Paris, 2004.

BARBUJANI, Guido. A invenção das raças. São Paulo: Contexto, 2008.

BERNAL, M. A imagem da Grécia Antiga como uma ferramenta para o colonialismo e para a hegemonia europeia. In Pedro Paulo A. Funari (Org.). Repensando o Mundo Antigo. Campinas: IFCH/UNICAMP, 2005.

BLYDEN, E.W. A invenção de África: gnose, filosofia e a ordem do conhecimento. Luanda/Mangualde (Portugal): Edições Mulemba/Edições Pedago, 2013, p. 129-170.

CARDOSO, C.F.S. O Egito Antigo. São Paulo, Brasiliense, 1982.

COSTA E SILVA, A. A Enxada e a lança. A África antes dos portugueses. Rio de Janeiro, Nova Fronteira, 1992.

A manilha e o Libambo. A África e a escravidão, 1500 A 1700. Rio de Janeiro, Nova Fronteira, 2002.

- Um Rio Chamado Atlântico. A África no Brasil e o Brasil na África. Rio de Janeiro, Nova Fronteira, 2003.

FEITOSA, L. M. G. C.; FUNARI, P. P. A. (Org.); ZANLOCHI, T. S. (Org.) . As veias negras do Brasil: conexões brasileiras com a África. 1. ed. Bauru: EDUSC, 2012. v. 1. 
FONSECA, Maria Nazareth Soares. (org.) Brasil afro-brasileiro. Belo Horizonte: Autêntica, 2000.

FUNARI, R.S. Egypt and Brazil. In: New perspectives on the ancient world. Oxford, Archaeopress, 2008. p. 73-76.

FUNARI, R.S. Imagens do Egito Antigo. São Paulo, Annablume/Unicamp, 2006.

FUNARI, R.S. O Egito dos faraós e sacerdotes. São Paulo, Atual, 2001.

FUNARI, R.S. O interesse pelo Egito faraônico: uma aproximação inicial. In: História Antiga, contribuições brasileiras. São Paulo, Annablume/Fapesp, 2008. p. 93-100.

GORENDER, Jacob. O escravismo colonial. 6 ed. São Paulo: Ática, 2001.

GRALHA, J.C.M. Egípcios. In: As religiões que o mundo esqueceu. São Paulo, Contexto, 2009. p. 11-27.

HEYWOOD, Linda M. Diáspora negra no Brasil. São Paulo: Contexto, 2008.

JOHNSON, P. História Ilustrado do Egito Antigo. Rio de Janeiro, Ediouro, 2002.

KI-ZERBO, Joseph (Coord.). História geral da África. São Paulo: Ática/Unesco, 1982.

KI-ZERBO, Joseph (Ed.). História geral da África: I: Metodologia e pré-história da África. Trad. MEC/Centro de Estudos Afro-Brasileiros da UFSC. São Paulo/Brasília: Cortez/UNESCO, 2011.

MAESTRI, Mário. A Servidão Negra. Porto Alegre: Mercado Aberto, 1988.

MAESTRI, Mario. História da África Negra Pré-Colonial. Porto Alegre: Mercado Aberto, 1988.

MATTOS, Regiane de. História e cultura afro-brasileira. São Paulo: Contexto, 2008.

MESKELL, L. Intimate archaeologies. The case of Kha and Merit. World Archaeology: Intimate Relations, 29/3. p. 363-379.

MESKELL, L. Size matters: sex, gender and status in Egyptian iconography. In J. Hope et al. (eds) Redefining Archaeology: Feminist Perspectives. Canberra, ANU Press: Canberra, 1998. p. 175-181.

MESKELL, L.; JOYCE, R. Embodied lives. Figuring ancient Maya and Egyptian experience. Londres, Routldege, 2003. 
MUNANGA, Kabenguele. Rediscutindo a Mestiçagem no Brasil. Identidade Nacional versus identidade negra. Petrópolis, Rio de Janeiro: Vozes, 1999.

NASCIMENTO, Abdias. O Quilombismo. Documentos de uma militância pan-africanista. Brasília: Fundação Cultural Palmares/ Rio de Janeiro: OR Editor Produtor Editor, 2002.

PINSKY, J. As primeiras civilizações. São Paulo, Contexto, 2008.

Reis, J.J. GOMES, Flávio dos. Liberdade por um Fio. São Paulo: Companhia das Letras, 1996

SCHWARCZ. Lilia Moritz. O espetáculo das raças. cientistas, instituições e questão racial no Brasil no Brasil do século XIX. São Paulo: Companhia das Letras, 1993.

SHAW, I. Ancient Egypt. Oxford, Oxford University Press, 2004.

SILIOTTI, A. Primeiros descobridores. A descoberta do Egito. Barcelona, Folio, 2007.

SILIOTTI, A. Viajantes e exploradores. A descoberta do Egito. Barcelona, Folio, 2007.

STEER, D.A. Egiptologia. São Paulo, Briquebooks, 2009.

THORTON, John. A África e os africanos na formação do Mundo Atlântico, 14001800. Rio de Janeiro, Campus, 2003.

VERCOUTER, J. Em busca do Egito esquecido. São Paulo, Objetiva, 2002.

VIDAL-MANZANARES, C. Diccionario histórico del antiguo Egipto. Madri, Alianza, 1993. 